\title{
SUCCESSFUL TRANSPLANTATION OF HUMAN AND CAT CORNEAL TISSUE INTO RABBIT CORNEAE*+
}

\author{
BY \\ D. P. CHOYCE
}

London

IT is always regarded as axiomatic that there is no possibility of a corneal graft being successful unless the donor material comes from an animal of the same species (Nižetić, 1934; Duke-Elder, 1938; Lister, 1951; Avello, 1951; etc.), but this dogma is open to question.

Ortin $(1914,1916,1931)$ performed penetrating grafts on rabbits, using donor material from other species; in every case a permanent opacity resulted. He did not state, however, whether the operations had been technically successful and free from complications. For example, adherence of the iris to the graft would by itself have caused opacification of the graft apart from the question of tissue incompatibility between donor and host.

Experimental lamellar heteroplasties do not appear to have attracted much attention. Von Walther (cited by Mühlbauer, 1840) made some experiments on animals and operated on a few clinical cases; these efforts were not successful and the report omits histological data and other important details. As no more satisfying reports could be found in the literature it was decided to attempt to fill in this gap in our knowledge.

\section{Present InVestigations}

Lamellae of corneal tissue superficial to Descemet's membrane were taken from human and cat eyes and grafted into rabbit corneae. It was proposed

(a) to kill some animals at lengthening intervals after grafting, in order to study the histological changes taking place,

(b) to keep others alive for a minimum period of 2 years, to study the delayed results of these grafts.

\section{TECHNIQUE}

The author (Choyce, 1949) described a technique of performing lamellar keratoplasties in rabbits, in which the graft was not held in place by sutures, but was retained by being inserted along the plane of cleavage existing between Descemet's membrane and the deeper layers of the substantia propria. It is rare for the graft to be dislodged after using this technique, and all the experiments to be described in this paper were performed

* Received for publication June 5, 1952

† Dedicated to Professor Lindner on the occasion of his 70th birthday. 
in this manner. This technique is illustrated by Figs 1 and 2 . For full details of the operative technique reference should be made to the original article.

No bilateral heteroplasties were performed.

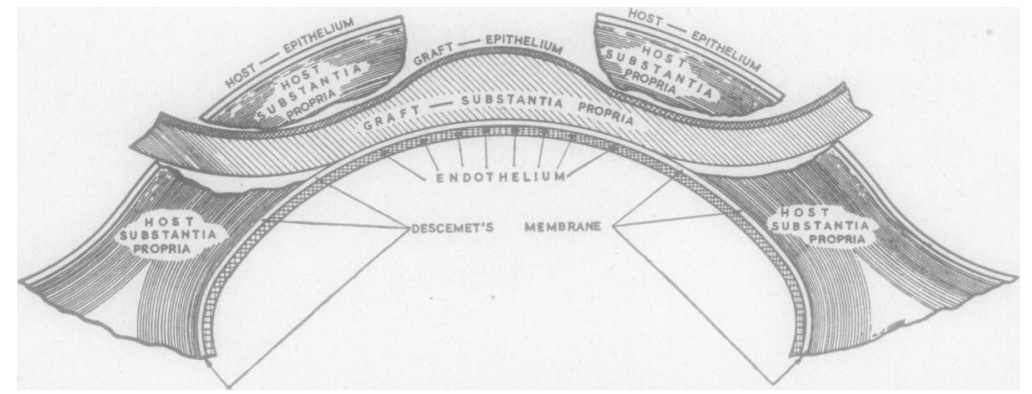

FIG. 1.-Diagram to illustrate intracorneal lamellar keratoplasty (Choyce, 1949).

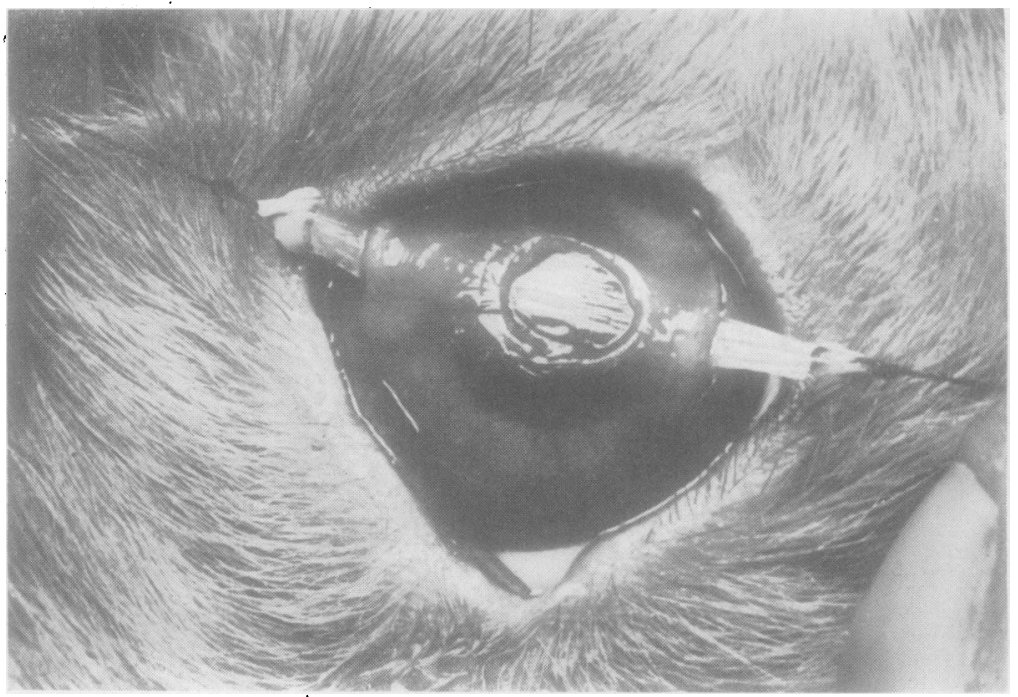

FIG. 2.-Strip of cornea in situ (Choyce, 1949).

\section{Clinical Results}

In any series of survival experiments certain animals die prematurely, e.g., from the effects of the anaesthetic, intercurrent infection, or injuries received from other rabbits in the same cage. These are excluded from consideration. In this particular series a proportion of the animals scratched at their operated eye causing severe ophthalmia. Most of these had to be killed because they were in obvious pain. These also were excluded from analysis of the results.

Some fifteen animals were left for study:

(1) Nine cases of lamellar strip keratoplasty using donor material from cats.

(2) Five cases of lamellar strip keratoplasty using human donor material. 
(a) ImMediate Results.-The post-operative appearances for both classes of donor material were much the same and bore a striking resemblance to the course of events following homotransplants, as described by the author (Choyce, 1949). The central area of the graft was oedematous; as this subsided translucency returned. There was a variable degree of interstitial keratitis in which superficial and deep vessels invaded the operated area from the two extremities, but in no case was the central area vascularized. After 2 to 3 weeks these vessels disappeared but they could still be detected with the slit-lamp microscope.

(b) Delayed Results.-After 6 or 7 months, the corneae had all healed well. The central areas were translucent and of even surface, as shown by the fact that it was possible to obtain an undistorted view of the rabbits' fundi on direct ophthalmoscopy. Faint markings indicated the sites of operation (Fig. 3).

Fig. 3.-Result of strip lamellar heteroplasty after 7 months. The strip runs from 2 o'clock to 8 o'clock (Choyce, 1949).

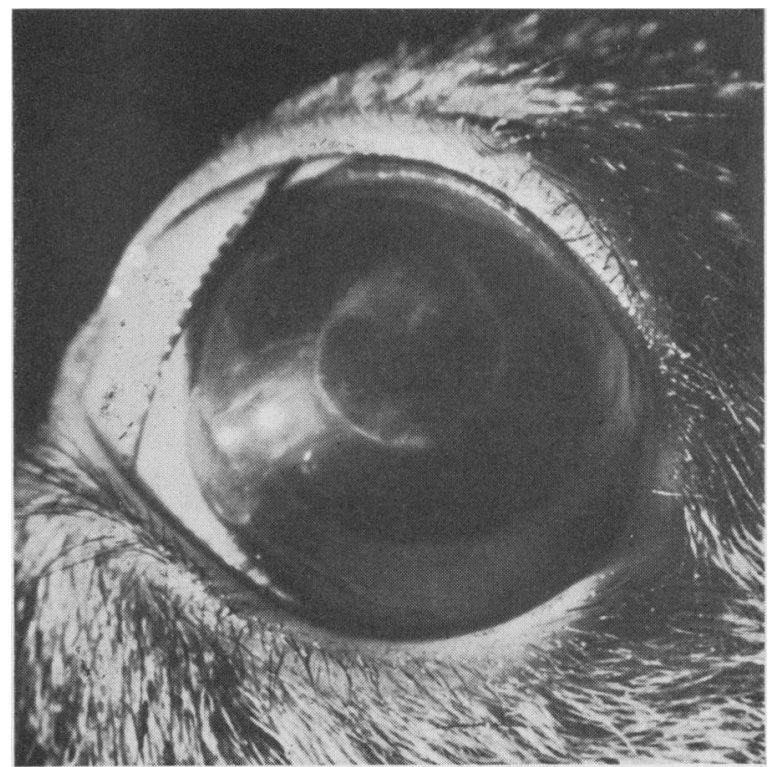

After 2 years it was extremely difficult to make out these sites, so well had the grafted tissues been assimilated by the host. The grafts were still perfectly clear. and there was nothing to suggest that they would not remain translucent indefinitely. All signs of post-operative keratitis had long since disappeared, there were no ghost vessels, and the operated eyes were almost indistinguishable from their unoperated fellows. In several cases the record made at the time of operation was the only means of deciding which eye to excise for histological examination.

The animals were killed, and the eyes were submitted to histological study. The time which had elapsed since operation varied between 22 and 27 months (average 24 months). 


\section{Histological Results}

(a) EARLY FINDINGS.-Reference should be made to the adjoining paper by Babel and Bourquin, which includes an account of the histological findings from 8 days to $3 \frac{1}{2}$ months after a similar series of operations.

(b) Findings Two Years AFTER Grafting.-Vertical sections were made of the corneae along the axes of the operations. In some of the eyes it was very difficult to make out the site of the operation. Figs 4 and 5 show the low-

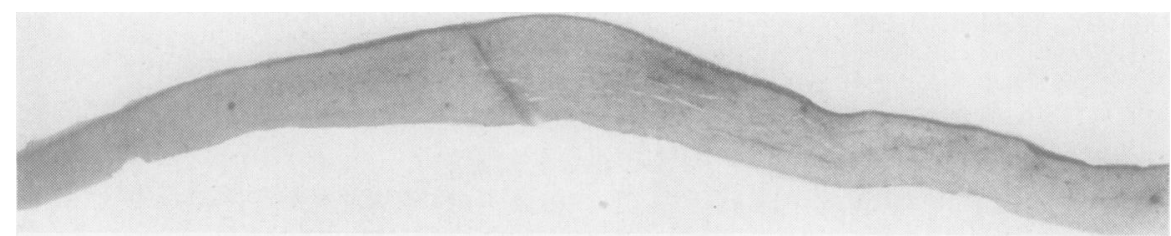

FIG. 4.-Two years after performance of heteroplasty, using human donor material (low-power view).

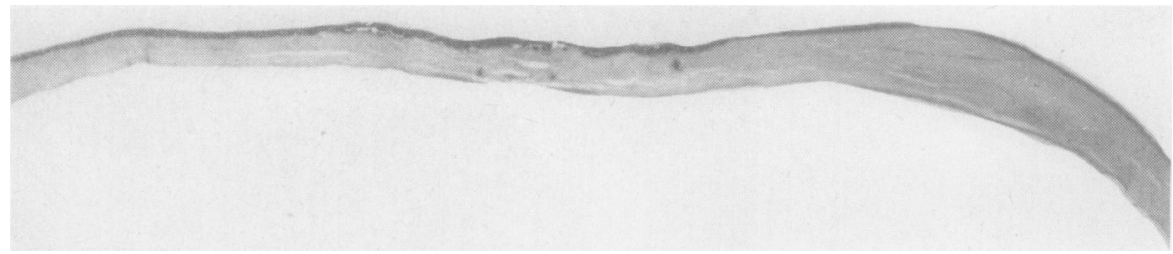

Fig. 5.-Two years after performance of heteroplasty, using donor material from cat (low-power view).

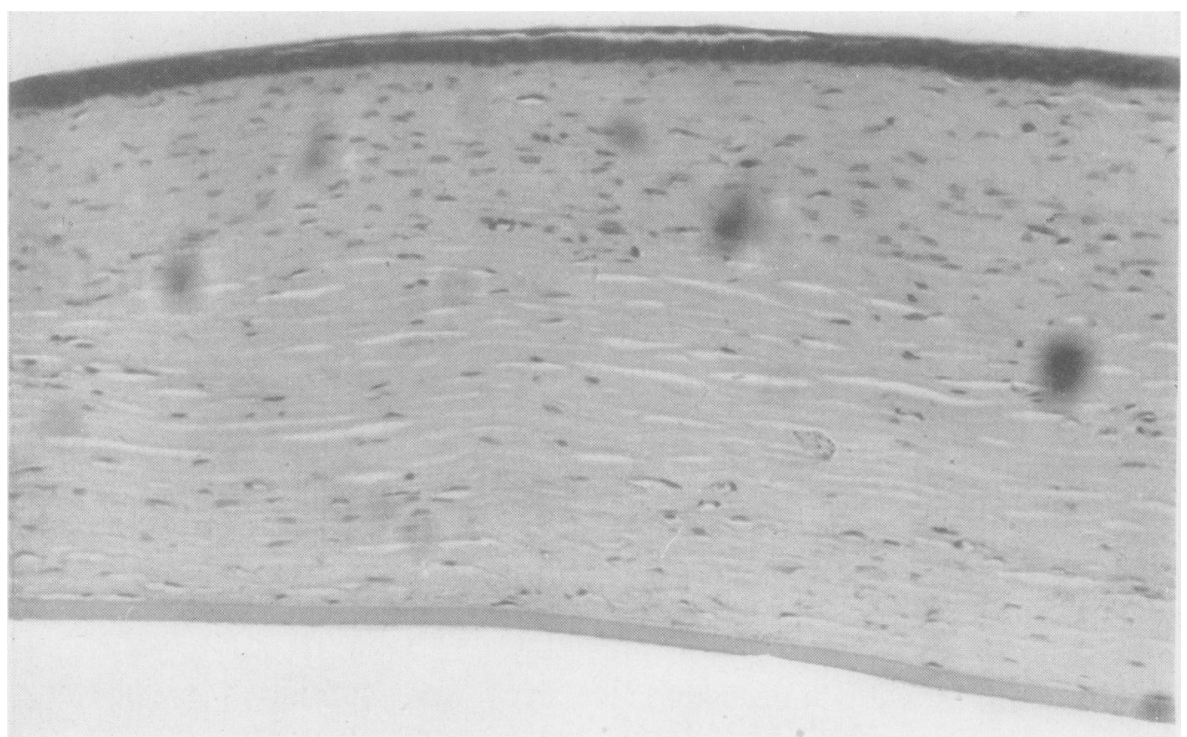

FIG. 6.-Human heteroplasty (high-power view). 


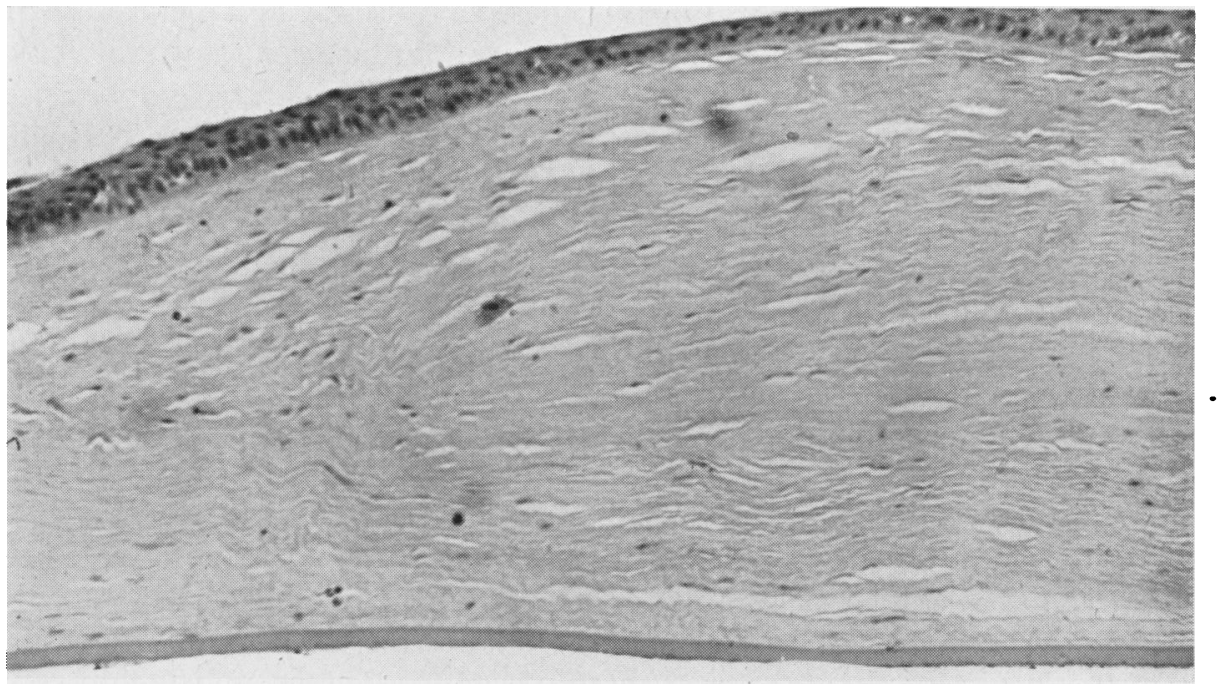

FIG. 7.-Cat heteroplasty (high-power view).

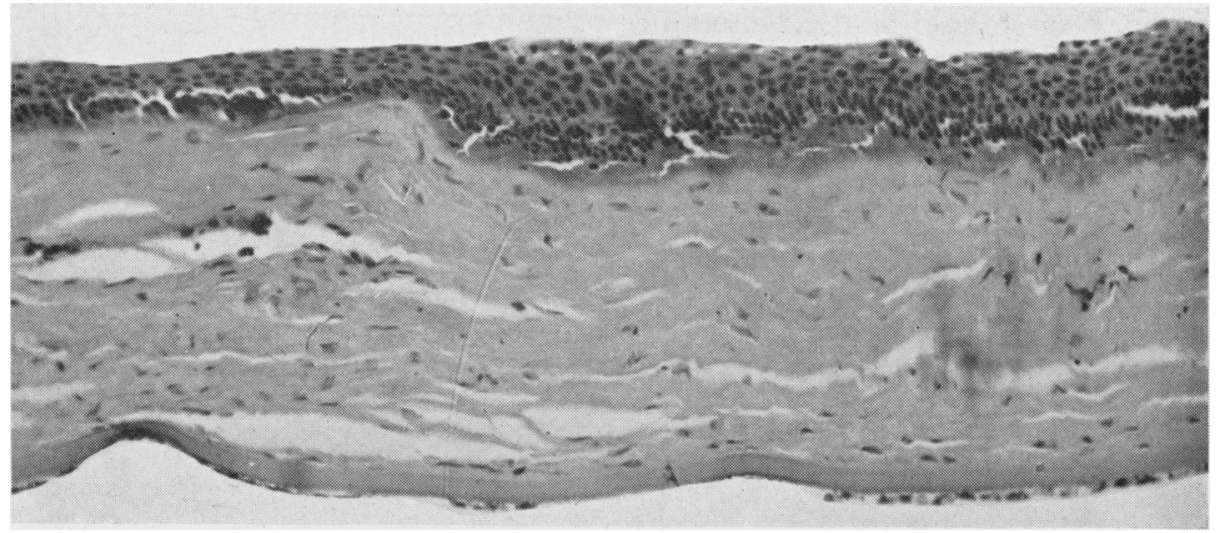

FIG. 8.-Cat heteroplasty, showing irregularity of surface epithelium (high-power view).

power appearances of human and cat heterografts respectively, and Figs 6 and 7 the appearances under high power. It will be noted that there is remarkably little departure from the normal. Slight irregularity of the surface epithelium may be noted at one or two points (Fig. 8) but otherwise little abnormality is seen. There is no trace of the buried foreign epithelium. The dimensions of the corneal corpuscles of man, cat, and rabbit are quite different, and yet the fibres here shown appear to be homogenous and typical of those of the host.

Discussion.-The only possible interpretation of these histological appearances is that, after 24 months, every component of the heterograft has been 
replaced by host cells-epithelium, corneal corpuscles, and nerves. This process has been effected without disturbing the translucency of the whole.

The wider implications of these results are of considerable importance, from both scientific and practical aspects. Since two workers, proceeding independently of each other, have shown that experimental lamellar heteroplasties are a practical possibility in the rabbit, this may be regarded as an established fact. Logically the next step would be to try to perform penetrating heteroplasties in rabbits, and if these were successful the experiments might be repeated further up the zoological scale, e.g., grafting human corneal tissue into Rhesus monkeys. From the scientific stand-point these experiments should illuminate the vexed problem of the " fate of the graft ", while on the practical side there is always the possibility of finding alternative donor material suitable for use in human eyes. The rabbit cornea seems to be very remarkable in many ways, and it would be a mistake to conclude, because it is possible successfully to graft human corneal tissue into the rabbit cornea, that the reverse is also true. Nevertheless, it is acknowledged that the great impediment to graft surgery in Great Britain, up to the present time, has been the lack of suitable donor material. This problem would be grealy simplified if further experiments showed that corneal tissue from other species could be used instead of human donor material.

\section{SUMMARY}

(1) Lamellae of corneal tissue from cat and man have been successfully grafted into rabbit corneae.

(2) After 2 years the host corneae were almost indistinguishable from normal, and there was no suggestion that the grafts would not remain translucent indefinitely.

(3) The significance of these observations is discussed.

The costs of this research were met by a grant from the Medical Research Council. My thanks are due to the Pathology Department (Dr. Norman Ashton) and the Medical Illustration Department (Dr. Peter Hansell) of the Institute of Ophthalmology in preparing the sections and the illustrations, and to the Editors of the Transactions of the Ophthalmological Society of the United Kingdom for permission to reproduce Figs 1, 2, and 3.

\section{REFERENCES}

Avello, J. V. (1951). Arch. Soc. oftal. hispano-amer., 11, 518.

CHOYCE, D. P. (1949). Trans. ophthal. Soc. U.K., 69, 55.

DukE-ELdER, S. (1938). "Text-book of Ophthalmology", vol. 2, p. 1837. Kimpton, London. LISTER, A. (1951). Ophthal. Lit., Lond., 5, 67.

MüHlbauer, F. X. (1840). "Ueber die Transplantation der Kornea". München.

NižETıĆ, Z. (1934). Klin. Mbl. Augenheilk., 93, 89.

OrTIN (1914). Act. Asamblea Soc. oftal. hispano-amer., 18, 161.

(1916). Ibid., 20, 565

(1931). Med. Ibera, 2, 213. 